\title{
Marco Nuti, Il sacro, l'osceno, il diverso. Scritture della devianza nel Novecento europeo
}

\section{Gabriella Bosco}

\section{(2) OpenEdition}

1 Journals

\section{Edizione digitale}

URL: http://journals.openedition.org/studifrancesi/8142

DOI: 10.4000/studifrancesi.8142

ISSN: 2421-5856

\section{Editore}

Rosenberg \& Sellier

\section{Edizione cartacea}

Data di pubblicazione: 1 juillet 2009

Paginazione: 463

ISSN: 0039-2944

\section{Notizia bibliografica digitale}

Gabriella Bosco, «Marco Nuti, Il sacro, l'osceno, il diverso. Scritture della devianza nel Novecento europeo», Studi Francesi [Online], 158 (LIII | II) | 2009, online dal 30 novembre 2015, consultato il 12 janvier 2021. URL: http://journals.openedition.org/studifrancesi/8142; DOI: https://doi.org/10.4000/studifrancesi. 8142

Questo documento è stato generato automaticamente il 12 janvier 2021.

\section{(c)}

Studi Francesi è distribuita con Licenza Creative Commons Attribuzione - Non commerciale - Non opere derivate 4.0 Internazionale. 


\title{
Marco Nuti, Il sacro, l'osceno, il diverso. Scritture della devianza nel Novecento europeo
}

\author{
Gabriella Bosco
}

\section{NOTIZIA}

MARCo NUTI, Il sacro, l'osceno, il diverso. Scritture della devianza nel Novecento europeo, Firenze, Editrice Clinamen, 2007, pp. 149.

1 Il saggio di Marco NUTI prende in esame una serie di fenomeni letterari caratterizzati dalla devianza, percepita come «pensosa risposta agli interrogativi del nostro tempo». I testi analizzati comunicano tra loro formando una fitta rete di associazioni, convergenze, biforcazioni ma anche tracciando un itinerario, viaggio alla scoperta della differenza. L'asse centrale del discorso sta nella ricerca del possibile punto d'incontro tra sacro, osceno e diverso. L'emergere del negativo, nella letteratura novecentesca, si accompagna al dissolversi delle grandi ideologie e allo smarrirsi dei solidi e rassicuranti riferimenti tradizionali: gli autori indagati, in altri termini, esprimono lo strappo e lo smarrimento dell'uomo contemporaneo. Ma anche creano, a partire dalla decostruzione, nuovi rapporti tra l'individuo e il mondo, tra il soggetto - fattosi plurale e instabile - e una sacralità diversa, che emerge dal silenzio, dall'abisso. La scrittura cresce tra le rovine della sua leggibilità facendosi magmaticamente e dirompentemente eversiva, andando alla deriva ma nondimeno delineando un discorso, in qualche modo di grande coerenza, seppure Altra, in apparenza anarchica e ciononostante profonda e unitaria.

2 I dieci capitoli del saggio percorrono così, senza la pretesa di essere esaustivi né sistematici, il xx secolo, andando però a cercare le radici del fenomeno letterario della devianza nell'Ottocento, e spaziando nella creatività europea: dalla rappresentazione del disagio fisico nella schiera di personaggi che popolano l'universo mentale di Henri 
Michaux («Henri Michaux e l'elogio dell'infermità», pp. 9-22), alla provocatoria profanazione della sacralità della pittura e della sua secolare mimesis testimoniate tanto da Gilles Deleuze quanto da Francis Bacon («Strategie della rappresentazione. Desacralizzazione dell'immagine figurativa tra Deleuze e Bacon», pp. 23-35); dall'affascinante lettura klossowskiana di una modernità luttuosa («L'allegoria cristiana della modernità. Le Baphomet di Pierre Klossowski», pp. 37-47) all'ibridazione cinematografico-letteraria in Robbe-Grillet - definizione che l'autore delle Gommes avrebbe certamente contestato («Mélanges scritturali. Il cine-romanzo di Alain RobbeGrillet», pp. 49-63); dal disagio psichico che la scrittura della catastrofe kafkiana drammaticamente mette in atto («Franz Kafka e la scrittura della reclusione», pp. 65-78) al carattere modernamente ieratico della poesia di Jaccottet («Philippe Jaccottet e il sacro», pp. 79-85); dalla sconcertante oscena impudicizia corporale dei personaggi batailliani che, nella deliquescenza della materia, urlano un anelito di libertà assoluta («Georges Bataille e la fisiologia dell'osceno», pp. 87-99) all'esplorazione sovversiva e alla contaminazione di spazi geografici "borghesemete civilizzati" nell'estetica surrealista («Cartografie surrealiste», pp. 101-113); infine dalla frammentazione dolorosa del soggetto poetico tra io plurimi e dissolvimento identitario in Joyce e Musil («Io-Noi/ Io-Altro. Deflgrazioni del soggetto da Baudelaire a Joyce», pp. 115-129) al sereno e enigmatico distanziamento del lettore dalla sacra inaccessibilità della scrittura in Blanchot («Maurice Blanchot e lo spazio della lettura», pp. 131-149).

3 Sottesa all'indagine è la presa di coscienza del dischiudersi di un ambiguo e contraddittorio, ma non per questo meno vero, orizzonte di senso assoluto. 